\title{
Cosmópolis: la paradoja de Aquiles y la tortuga
}

\section{(Cosmopolis: the paradox of Achilles and the tortoise)}

\author{
ANGÉLICA GARCÍA-MANSO/ FrANCISCO JAVIER TOVAR PAZ \\ angmanso@unex.es/fjtovar@unex.es \\ Universidad de Extremadura
}

Fecha de recepción: 30 de mayo de 2018

Fecha de aceptación: 28 de diciembre de 2018

Resumen: Cosmópolis es al mismo tiempo el título de una novela de Don DeLillo y el de un filme de David Cronenberg basado en la primera. A partir del contraste entre ambos, novela y película, se lleva a cabo una lectura desde la perspectiva de la Tradición Clásica; más en concreto, sobre la cronología en la narración y sobre las paradojas temporales presentes de forma más evidente en la adaptación de Cronenberg. De acuerdo con ello, Cronenberg refleja cómo el arte cinematográfico, frente al literario, permite una percepción del viaje a la muerte desde el interior de la imagen. En dicho viaje se cruzan motivos odiseicos y, sobre todo, la clásica paradoja del espacio y el tiempo de Zenón de Elea conocida con el título de Aquiles y la tortuga.

Palabras clave: Cosmópolis. DeLillo. Cronenberg. Tradición Clásica. Paradoja de Aquiles y la tortuga.

Abstract: Cosmopolis is both the title of a novel by Don DeLillo and a film by David Cronenberg based on the first one. From the contrast between the two, novel and film, a reading is carried out from the perspective of the Classical Tradition; more specifically, on the chronology in the narration and on the temporal paradoxes present in a more evident way in Cronenberg's adaptation. In this way, Cronenberg reflects how film art, as opposed to literary art, allows a perception of the journey to death from within the image. In this journey, homeric motifs about Odysseus are crossed with the classic paradox of the space and time of Zenon of Elea, known by the title of Achilles and the turtle.

Keywords: Cosmopolis. DeLillo. Cronenberg. Classical Tradition. Paradox of the Tortoise and Achilles. 


\section{Introducción: la novela de DeLillo y el filme de Cronenberg}

Más allá de las reseñas de carácter divulgativo y las menciones en estudios de conjunto sobre la novela norteamericana contemporánea o sobre el actual cine estadounidense, no abundan en España los análisis sobre la obra de Don DeLillo ni sobre la filmografía de David Cronenberg, si bien se podría decir que suele darse un mayor interés por la creación del cineasta (Gorostiza y Pérez 2003) que en torno al escritor (Otero 2004), sin que se cuente apenas ningún análisis de carácter académico relacionando a ambos creadores, es decir, apenas existen trabajos acerca de la obra Cosmópolis, novela y filme (Garrigós 2015); no sucede lo mismo con la bibliografía fuera de España (Duvall 2008; en lo que se refiere a la novela), según se va a considerar en nuestro estudio y en las entradas bibliográficas que lo sustentan.

En esta coyuntura cabe interrogarse directamente por aspectos de la trama de Cosmópolis que se comparten y que son divergentes en el proceso de interrelación Literatura/Cine y cómo tal proceso condiciona la lectura última de las obras por separado y, sobre todo, permite descubrir la aportación singular que puede ofrecer la versión fílmica a un relato que, normalmente, es anterior a la adaptación (pues podría darse el fenómeno contrario: una edición a posteriori de la versión literaria de un filme) y que funciona bajo reglas diferentes. No obstante, al margen de las propias referencias que se hacen al Séptimo Arte en la novela, esta ha sido leída en clave fílmica, como una película sin imágenes (Heyne 2013). Finalmente, cabe interrogarse sobre cómo influyen los paralelismos que se ofrecen desde la perspectiva de la tradición cultural en general y clásica o grecolatina en particular, según se tendrá ocasión de comprobar a lo largo del presente estudio ${ }^{1}$, pues derivan en enfoques diferentes en el tratamiento textual y el filmico. De ahí la importancia de referentes como los shakespirianos o, directamente, de temas de la antigüedad clásica en sendas manifestaciones, la literaria y la cinematográfica.

Ambas orientaciones (la interrelación Cine/Literatura y la Tradición Clásica) se apoyan metodológicamente en las propuestas del Comparatismo (según hemos establecido, en, por ejemplo, Tovar 2007; cf. también García Jurado 2015), además de la propia Tradición Clásica. Por lo demás, la literatura secundaria actual acerca de las interrelaciones Cine/Literatura es muy amplia, si bien existen presupuestos no comparatistas que se refieren a los mutuos referentes paratextuales entre guion y novela de acuerdo con los presupuestos ya clásicos de Genette (1989).

${ }^{1}$ Como, según se desprende del título, la paradoja clásica de Aquiles y la Tortuga, la cual, al margen de menciones puntuales en otros filmes o de su tratamiento en dibujos animados serializados, ha sido recientemente objeto de abordaje en un filme de Takeshi Kitano, en Akiresu to kame (2008), acerca de un pintor en búsqueda de un éxito que continuamente se le va de las manos. 
En efecto, la clave narrativa de la trama se puede atisbar en el cuestionamiento acerca de qué ha impulsado a Eric, protagonista primordial si no único del relato que transcurre en Cosmópolis, a programar el día de su muerte, o, al menos, a constatar su existencia como si estuviera ya muerto (sin relación alguna con el género de terror al respecto, sino de una forma más existencial o filosófica. Se trata de la sensación de estar muerto y de haberse acabado su tiempo, una idea que puede ponerse en relación con la clave heideggeriana del "ser para la muerte" (Heidegger 2012; Tovar 2012²) y, de manera más certera, en el ámbito de la hipernarcisista "era del vacío" que se ha popularizado como expresión por Gilles Lipovetsky (1994). La respuesta se descubre entre líneas, sea en la lectura del texto de Don DeLillo (cuya primera edición original es del año 2003, con traducción al español en el año 2005), sea en las imágenes del filme de David Cronenberg que lo adapta casi una década después de su publicación, en el año 2012. Acaso tal cuestión constituya más bien el enigma de fondo que incomoda al lector o al espectador en tanto asiste a las peripecias de las últimas horas de vida del personaje en el libro o en pantalla (Sciolino 2015).

Sin embargo, desde una perspectiva propiamente histórica, entre la novela y el filme ha transcurrido un tiempo relevante, casi una década, con marcadas diferencias: así, en DeLillo se muestra una forma de entender la existencia humana -como una especie de juego de la ruleta rusa que pone en funcionamiento el poder financiero y las reacciones ante pulsiones autodestructivas de sus gerentes (Merola 2012; Mirbabazade \& Jafari 2013) - en unos momentos de crecimiento económico espectacular, donde solamente Japón parece sufrir síntomas de atonía y ni siquiera se ha producido aún la destrucción de las Torres Gemelas neoyorquinas (si bien la propia novela de DeLillo ha sido leída en clave anticipadora a este respecto; Laist 2010). Por el contrario, en Cronenberg se ha generalizado el terrorismo globalizado y ha sucedido la crisis planetaria del 2008, provocada por la especulación que había hecho inmensamente ricos a personajes como el que juega con su destino en la novela (Clavin 2017), cuya acción se desarrolla a comienzos del nuevo milenio, dos o tres años antes.

De acuerdo con ello, de alguna manera DeLillo considera el declive milenarista de un sistema que ha llegado a sus máximas expectativas de crecimiento sin encontrar otras metas posibles y solamente puede colapsar por sí mismo, como si lo hiciera por propia voluntad, por ser capaz de ello como mero ejercicio del enorme poder que detenta. Por su parte, Cronenberg, aun siguiendo

2 En relación con la influencia de Heidegger en el filme La Delgada Linea Roja (The Tbin Red Line, 1998), de Terrence Malick. 
de forma precisa el texto de DeLillo, aborda una perspectiva singular y distorsionada acerca del citado colapso. Por ejemplo, las "ratas" que se invocan como moneda de cambio en la apertura de la novela de DeLillo constituyen una premonición apocalíptica a partir de un verso de Zbigniew Herbert (Sánchez 2014: 273), es decir, se trata casi de un recurso de descripción política en forma de protesta anticapitalista (Rodica 2012); por su parte, las "ratas" en Cronenberg responden a una realidad social que empieza a ser demasiado palpable si no en Nueva York sí en el resto de lo que se entendía como "primer mundo", aunque, en realidad, el propio sistema las haya asimilado en buena medida tiempo después.

Lo mismo sucede en otros episodios o momentos de la trama, como el asesinato de un banquero en el lejano Oriente o el golpe de pastel que recibe en su cara el protagonista; o, en fin, con los motivos que impulsan al ejecutor de su asesinato: se ha pasado de la protesta política hacia la violencia social, o, cuando menos, hacia su conato. Los temas abordados sugieren cómo la distorsión entre texto y película es de carácter temporal: lo que en De Lillo se puede leer como profecía per se, es decir, enfocada hacia el futuro, en Cronenberg sucede a la inversa, como una "falsa profecía", una mirada que evoca un pasado que ha dejado de existir.

\section{La muerte como reflexión sobre el poder en Cosmópolis}

Según se puede apreciar en relación con la idea de profecía -sobre la debacle económica y sobre la crisis general- y según se considerará de forma más detallada en un epígrafe posterior, el tema del tiempo constituye uno de los ejes centrales del relato (Noble 2008). A este respecto, la muerte que programa Eric constituye, probablemente, el momento de su existencia más paradójico, sobre todo porque, frente al momento del nacimiento, en el que no existe conciencia de lo trascendente, sí se puede ser consciente del momento que depara el destino o que se provoca para forzar dicho destino: así, de acuerdo con esta idea de paradoja, el momento de la desaparición del tiempo provoca su aceleración absoluta y, de forma simultánea para el sujeto, su detención y parálisis total. No faltan referencias a Eric -algo que se manifiesta de forma más evidente en DeLillo que en Cronenberg- tratado como la conciencia de un muerto que repasa su vida. De alguna manera, por esa razón el protagonista del relato vive a lo largo de la trama una experiencia vital concentrada en las horas de luz de un único día, desde la mañana a la noche, pero se trata de un día concebido como una versión veloz y, a su vez, repetida o cíclica, de su periplo vital completo.

La experiencia culmina con un reto a la desaparición del personaje, pues este toma la decisión de arruinarse $y$, simultáneamente, de dar cumplimiento a su 
propia muerte. Lo hace a manos de otro personaje de la novela que solamente tiene cabida en la última parte del filme, siendo éste, probablemente, el punto de mayor divergencia entre novela y película. Y es que DeLillo concede voz propia (es decir, al margen del punto de vista de Eric, que predomina en el relato) al personaje de Benno, su asesino, una figura mucho más borrosa y casi sin entidad en el filme, para lograr así un suicidio que parece programado a distancia. El ejecutor responde a la de una figura más propia del texto que de la imagen. Así, de los sucesos y las reflexiones se desprende que Eric, a fuerza de poseerlo todo (además de haber logrado triunfar en el mundo de las finanzas en un tiempo récord; dada su juventud), ha perdido el deseo, pero refuerza su capacidad de no temer a nada y a nadie, ni siquiera a su propia muerte. Su postura a este respecto se revela hierática, propia de un existencialista.

Más aún, consciente de su poder, el personaje lo pone a prueba de una forma de raigambre literaria, a la manera que reflejan textos del siglo XX inspirados en el mundo antiguo como, entre otros, el drama Calígula de Marcel Camus (Paris: Gallimard, 1944) o la novela Los idus de Marzo de Thornton Wilder (New York: Harper \& Brothers, 1948). En efecto, en los títulos mencionados tanto Julio César como Calígula traman su propia muerte, su asesinato; y lo hacen sin designar a un homicida concreto, e incluso se sorprenden al descubrir la persona específica que empuña el arma que acabará con su vida. A este respecto, el comportamiento de Eric al matar a Torval, su guardaespaldas, refleja un dominio de las vidas ajenas que lo hace equiparable al emperador romano de Camus. Por otra parte, Torval ha actuado en todo momento como agorero mensajero del peligro que se cierne sobre el protagonista (tema heredado del drama shakespeariano en torno al asesinato de Julio César), sin ser consciente de que, en buena medida, tal destino ha sido programado por el propio Eric; en otras palabras, el desdén con que se hace frente a las amenazas a lo largo de su viaje procede de que él mismo es quien ha provocado las circunstancias que conducirán a su muerte a la manera de Julio César según se plasma en la novela ya clásica de Thornton Wilder. Al tiempo, se dota a la peripecia de Eric de un aire eminentemente trágico, de acuerdo con los parámetros con los que se lee la Historia Antigua o se reinterpreta ésta a través de la obra Shakespeare, más concretamente a través de su Julio César (London: First Folio, 1623).

$\mathrm{El}$ interés de Eric por saber quién es Benno (o más bien, qué es, a qué se dedica), su ejecutor, queda así enmarcado en las circunstancias de las muertes que se muestran en el relato, fundamentalmente dos, muy diferentes entre sí: el asesinato en Corea de un director ejecutivo del Fondo Monetario Internacional y la muerte natural del rapero sufí cuyo funeral atasca el tráfico en las calles neoyorquinas. El primero es resuelto por Cronenberg de forma elaboradamente 
cinematográfica, con un tempo y una elegancia operística próximos a lo que se descubre en la estética que emplea Francis Ford Coppola en su saga El Padrino (The Godfather, I, II \& III, 1972, 1974 \& 1990), que se ha convertido en clásica: se trata de un asesinato calculado fríamente, muy profesional y preciso, a manos de una mafia que está infiltrada por el propio poder económico y cuyo ámbito de actuación es planetario, globalizado. El segundo fallecimiento, sin embargo, aparece envuelto en equívocos y prejuicios, a los que hay que añadir la sorpresa por la falta de información que afecta al personaje, que no sabe que ha muerto el músico cuyas melodías más se aproximan, por paradójicas -un rapero callejero que es místico sufí-, a su percepción de la realidad. Los equívocos nacen de que el colapso del tráfico en la ciudad se debe tanto a la visita del Presidente de los EEUU como a la procesión fúnebre de alguien famoso, innominado aún; los prejuicios afectan a las causas de la muerte, que no se deben ni a un hecho violento ni a ningún tipo de abuso de sustancias prohibidas, ni siquiera a un suicidio, sino que responde a causas naturales. Además, de fondo subyace el hecho de que, en un mundo donde las noticias se conocen instantáneamente, el personaje carezca de información sobre la muerte del que era su referente musical, del que le atraen las letras de sus canciones y su voluntad mística.

En contraste, la muerte de Eric no va a ser ni profesional ni natural, aunque, según se ha señalado en líneas precedentes, sí azarosa en lo que se refiere al brazo ejecutor y a los motivos que impulsan a su asesino a matarlo. El asesino es un antiguo profesor, más tarde empleado de segundo rango en la empresa matriz de la que es dueño Eric, de donde fue expulsado; pero, en realidad, sus circunstancias responden a la presentarse como un "alter ego" del protagonista, a su reverso o negativo fotográfico. Por lo demás, la decisión y la manera de matar responden a un proceso de imitación: se mata al jefe porque otros han matado a su jefe, a quien culpan de su fracaso vital, a quien responsabilizan de su situación económica y de la de tantos otros que, por igual, tendrían motivos para matarlo pero no se atreven a hacerlo. Al cabo, la historia de Eric es la historia de Benno, su asesino: se necesitan mutuamente para existir, aunque se ignoren. De esta manera, existen los "Eric" porque existen los "Benno", y a la inversa, a pesar de su mutuo esfuerzo por ignorarse hasta el momento en que confluyen la conciencia individual de morir y la social de matar. De ahí que las amenazas de muerte anónimas deban ser tenidas muy en cuenta por los encargados de seguridad de los magnates, por los Torval de turno.

Por otra parte, la ejecución del personaje a manos de su, por así decir, reverso o negativo fotográfico encaja consiguientemente en el concepto de asimetría presente en el relato: la paradoja entre velocidad y estatismo en el acto de la muerte responde a este patrón; pero es que, además, el protagonista tiene una 
próstata asimétrica, aspecto en el que el personaje se había regodeado como símbolo de no sabe bien qué, como mera marca que le identifica con su ejecutor, aunque no sabe que Benno también la padece (tampoco el espectador lo sabrá, pues el dato únicamente aparece en el relato de DeLillo).

En fin, el corte de pelo del protagonista quedará también asimétricamente a medias una vez que, de manera brusca, este decide salir de la peluquería que había sido su destino a lo largo de toda la jornada. Se trata de un aspecto también rodeado de extrañeza: y es que la conversación con el chófer y el peluquero, en la que se entremezclaban anécdotas de la profesión de taxista que ambos compartieron en el pasado con la historia del propio chófer y del padre de Eric, culmina en la mostración de una pistola guardada en un cajón. Es entonces cuando el protagonista decide imprevistamente abandonar el local: se trata de la segunda pistola que ve Eric: con la primera él mismo había matado a Torval, ésta segunda le está reservada a él, como si el arma le hubiera sido devuelta con ese fin tras haberla arrojado lejos del cadáver del guardaespaldas. El cumplimiento de su propia profecía se ve así reforzado, una vez que, en apariencia, el protagonista ha llegado a su destino, a una barbería que es, en parte, su pasado y su futuro. Es allí donde encuentra el arma con la que morirá.

\section{El trayecto por la ciudad como odisea amorosa}

El periplo de Eric no sólo consiste en la programación de su muerte, sino que, en un plano más inmediato, también responde a la búsqueda de un encuentro sexual con su esposa, según es apreciable tanto en el formato textual como en su adaptación fílmica; de ahí que se pueda concebir el tema conjuntamente, como una lectura compartida entre novela y película. En este contexto, Elise, la mujer con la que Eric está recién casado (apenas habrían transcurrido unas semanas desde su enlace), se hace en todo momento presente en el decurso del relato: el protagonista la encuentra casualmente en un taxi detenido junto a la limusina, sin que ella acepte compartir el vehículo; Eric la busca más adelante en el interior de una librería y, poco después, a las puertas de un teatro; finalmente, cree encontrarla en el rodaje de una película. Más que azar, se trata de hitos entre los encuentros sexuales del personaje: y es que, tras cada encuentro sexual adúltero, Eric parece buscar a su esposa, quien a su vez continuamente pospone la relación amorosa entre ellos.

En principio, el arquetipo que mejor podría sintetizar esta situación es el de Apolo y Dafne, como una esposa escurridiza, que se vuelve inalcanzable cada vez que el héroe está a punto de abrazarla, ampliando así su deseo en una persona que parece haber colmado todos sus deseos. Los cabellos de Elise se presentan como una metonimia de su condición de Dafne. Existe empero una asociación 


\section{ANGÉLICA García-MANSO/ Francisco Javier TOVAR PaZ}

literaria y filmica concomitante, que puede haber servido como motivo inspirador: se trata de la película Eyes Wide Shut (1999), de Stanley Kubrick, basada en un relato de Arthur Schnitzler, cuyo componente onírico comparte la propuesta fílmica de Cronenberg. De hecho, la propuesta fílmica de Kubrick también posee un correlato en la Tradición Clásica (Tovar 2000).

De alguna manera, en el contexto descrito Elise representa otra de las asimetrías del personaje. En efecto, frente a la riqueza que encarna Eric, nacida de una economía basada en inversiones de riesgo en un mundo globalizado, Elise, que es millonaria por herencia familiar, se dedica al ocio en su sentido clásico, es decir, a una actividad cultural libre de requisitos económicos. Así, escribe poesía, busca libros, asiste a representaciones teatrales, participa, aunque sea como imaginaria figurante, en un filme, etcétera, a pesar de que, en buena medida, sus intereses parecen abocados al fracaso. El deambular por la ciudad de Elise parece a este respecto el reverso del viaje de Eric, pues no tienen un fin ni un destino específicos más allá de la búsqueda por sí misma, o, por así decir, casi ensimismada.

De cualquier forma, a pesar de que los viajes de sendos personajes resultan paralelos, en realidad se ofrecen como divergentes, mediante unas reglas de juego en el que él la busca a ella y ella le esquiva: en efecto, si el destino de Eric es afrontar la muerte, ella no quiere ser partícipe en esa aventura, que acaso intuya de manera subconsciente. Su fuga se articula en el movimiento continuo, de forma aparentemente azarosa a lo largo de diversas etapas y lejos de la parálisis de la limusina de su esposo. El comportamiento de Elise no deja de verse lastrado por una decisión tajante y apriorística: posponer el encuentro sexual con Eric, pero no como castigo por sus continuos adulterios -que no procura evitar-, sino como parte de la excitación para un hombre que vive del instante y al momento. Su actuación responde, al cabo, a un modelo literario, dado que, no en vano, ella es lectora, cultiva la poesía y es aficionada al teatro. $\mathrm{Y}$ es que los respectivos periplos de la pareja responden a dos lecturas diferentes de la idea de viaje fundamentada en la Odisea homérica. $\mathrm{O}$, de forma más cercana al propio DeLillo, en la que se descubre en el Ulysses de James Joyce (Paris: Sylvia Beach, 1922).

De hecho, el protagonista de Joyce responde a una inversión del relato homérico: un hombre que no viaja al encuentro de su esposa, sino que pretende evitarla, a lo largo de un periplo que no dura años, sino apenas un día, supone una lectura irónica -además de moderna, por descontado- del arquetipo del poema épico que le da título y que constituye su trasfondo. De igual forma, en DeLillo/Cronenberg se da un paso más en el cambio de perspectivas e ironías: Eric-Ulises busca a su antiguo peluquero y Elise-Ulises busca evitar el encuentro 
amoroso con su marido. Las etapas del viaje de un día se pueblan de encuentros con la poesía y las artes, con un funeral, con reflexiones de toda índole, etcétera, de forma concomitante a como sucede en Joyce, sólo que en Cosmópolis (novela y película) las etapas se muestran en unas ocasiones en relación con un cónyuge y en otras con el otro. Resultaría vano establecer correspondencias entre las etapas del Leopold Bloom en su deambular dublinés y los trayectos de Eric y Elise, cuando lo importante radica en la de idea de hilvanación de sus pasos en una huida hacia adelante a lo largo de un espacio cronológico y geográfico muy delimitados y con un fuerte componente irónico a partir del paralelismo que ofrece la tradición literaria. La mentira, en fin, atributo de Ulises no sólo se presenta a la hora de justificar el olor a sexo que desprende Eric según le denuncia en cada reencuentro Elise: un olor que procede de las relaciones que va teniendo el protagonista a lo largo de la jornada, y que él justifica precisamente por lo contrario, por la contención sexual y el deseo que le despierta su esposa.

Así pues, en la dicotomía planteada entre movimiento y detención, Elise adopta la primera opción, casi la ubicuidad, en tanto que, en el interior del automóvil, es precisamente la lentitud y la espera lo que prevalece como rasgo característico de Eric y a pesar del carácter instantáneo de las comunicaciones en red. Ambas cronologías comparten el espacio, de tal forma que la imposibilidad sexual de la pareja se debe a unos tiempos que fluyen en ritmos dispares, a pesar de que el hecho de que compartan el lugar lo permitiría.

\section{La polis como necrópolis: la catábasis o "descensus ad ínferos"}

Los títulos de la novela y el filme se hacen eco de una alusión topográfica, que, aunque de índole abstracta, ciertamente suele considerarse como uno de los atributos habituales de Nueva York en virtud de su condición de "cosmópolis", es decir, de urbe no sólo de grandes dimensiones, sino en la que convergen múltiples razas, religiones, creencias, naciones o patrias, o, en sentido opuesto, donde ninguna de tales caracterizaciones, $u$ otras, es relevante o significativa; o, más aún, donde se puede llegar a negar atribución alguna al respecto; se trata de la ciudad universal. No obstante, también se puede leer el título en clave tecnológica, sobre la ciudad global e instantánea que se habita en las redes en paralelo con el terrorismo supranacional (Leps 2014). De cualquier forma, la alusión del título, aun contando con sus raíces clásicas, posee también un evidente carácter futurista (generalizado por el género de la ciencia ficción a partir de los modelos clásicos de "ciudad ideal"), pues, al igual que palabras como "Metrópolis" y "Megalópolis", permite aunar a las ideas de "capitalidad" económica- y "autarquía" la de espacio fuertemente estructurado y moderno o posmoderno así como la de metonimia del conjunto del planeta. Tal naturaleza 


\section{ANGÉLICA García-MANSO/ Francisco Javier TOVAR PaZ}

no impide la clave técnica, que deviene aplicable al predominio absoluto de los recursos digitales y de la red informática: una ciudad y un mundo interconectados hasta el punto de constituir una ciudad global a la vez que virtual, aunque sin renunciar a su concreción urbana, de trazados rectos en la horizontalidad y verticalidad de Manhattan. De esta manera, y desde una perspectiva de índole nuevamente temporal, el tándem "velocidad de datos / estatismo urbano" se vuelve a hacer presente en la denominación de la ciudad descrita por DeLillo y puesta en imágenes por Cronenberg. De cualquier forma, al margen del título o los créditos 3 , la palabra "Cosmópolis" no aparece ni en el texto de DeLillo ni en las imágenes o el guión de Cronenberg.

De esta manera, en principio, el título sirve de contexto de las peripecias de Eric a partir de su inversión irónica: precisamente el "cosmos" u "orden" es lo que aparece roto en el personaje a través de las diferentes asimetrías que, según hemos señalado, se hacen perceptibles a lo largo del relato. Pero también, conforme al sentido de la ironía presente a su vez en el uso del término, se da cabida al desorden cuando ninguna categoría política, social o ideológica resulta relevante ni identificadora, dando como resultado cierto imperio de una especie de "ley de la selva", donde todo vale (como bien refleja la especulación económica que está en el origen de la crisis actual). En otras palabras, el título no hace sino reflejar una "distopía": de ello procede el aire de "ciencia ficción" que, de por sí, impregna las imágenes de Cronenberg, más que en el texto originario, con el consiguiente fracaso de la utopía que destila el lento viaje de Eric a lo largo de su travesía urbana.

De ahí, en definitiva, que la búsqueda de un corte de pelo tradicional suponga rememorar otro modelo de urbe: la que representaban el padre de Eric y el propio peluquero que fue taxista en aquella otra ciudad del pasado; es decir, en la ciudad como historia que es negada por la aceleración contemporánea. Se trata, por consiguiente, de la búsqueda de un modelo de ciudad que ha periclitado, capaz incluso de verse reducida al interior de un vehículo, al espacio de la misma limusina de Eric.

En un orden de cosas diferente, surge un momento onírico en la novela; sucede durante el transcurso de la separación entre el chófer y Eric. Se trata de un momento que es presentado con un tono, en cierta manera, "catabáquico" o de descenso infernal: la oscuridad de la noche se puebla de cuerpos desnudos,

${ }^{3}$ Los títulos de crédito, obra del artista californiano Justin Stephenson, de Cuppa Coffee Studios, se basan en pinturas de Jackson Pollock (Grugeau 2012) en lo que se refiere a los de apertura [más concretamente se inspirarían en el cuadro Number 31, de 1950], y en Mark Rothko en lo que se refiere a los finales, apareciendo referencias a este segundo pintor en el relato, tanto en la novela como en la película, sobre todo a propósito de su célebre Rothko Chapel (1971) en Houston (USA). 
esparcidos y como derrumbados sobre el asfalto, a los que se acerca el personaje y entre los que decide mimetizarse. La situación se enmarca en el rodaje de una película (algo, por lo demás, bastante habitual en las calles neoyorquinas), en una escena en la que conocerá a una mujer a la que Eric cree confundir con su propia esposa. La referencia fílmica resulta demasiado impresionista y elíptica en DeLillo, con alusiones incluso a escenas de películas en blanco y negro, y se presenta como una especie de puerta simbólica hacia el desenlace de la narración: el abandono de la limusina y el encuentro con Benno, su ejecutor. En Cronenberg, sin embargo, tal escena se omite, dado que, entre otros motivos, su aparición resultaría, en principio, metafílmica, aunque, de alguna manera, lo que Cronenberg hace es devolver la escena al ámbito literario de DeLillo dado que su finalidad es desentrañar el esquema profundo del relato, o, en otras palabras, su inspiración en el recurso estilístico o temático al "descensus ad inferos", y responde incluso al motivo órfico de la búsqueda de la esposa entre los muertos.

De esta forma, el trayecto adquiere en cierto sentido el tono de un viaje nihilista: es decir, se efectúa a través de una ciudad que se construye a partir de su desaparición continuada, o, también, según se puede entender, a partir de un anacronismo que es en la actualidad intrínseco. $Y$ es que la ciudad no se concibe como una superposición histórica y social, sino como la antítesis de sí misma como entidad dinámica: al desaparecer se vuelve muerta e inerte o detenida. En otras palabras, se presenta como necrópolis o ciudad de los muertos. Ello no hace sino confirmar cómo el periplo de Eric responde al modelo clásico de la catábasis, es decir, el descenso a los infiernos, donde cruzar la ciudad supone cruzar la Laguna Estigia y donde la limusina se convierte en su particular Barca de Caronte del personaje. El destino no puede ser otro que la conciencia de estar muerto.

En este contexto, la importancia de Benno en el relato deja de ser así la de mero brazo ejecutor de la decisión de Eric y pasa a poseer la condición de juez; el destino de Eric queda así expuesto en su resumen vital de veinticuatro horas antes de diluirse en la inexistencia. Precisamente, la sentencia que dicta Benno le declara culpable de nihilismo, anunciando su autodestrucción. Tal es la irónica crónica de la autodestrucción que recorre Cosmópolis.

\section{La disolución de los tiempos en la novela de DeLillo y el filme de Cronenberg: de la profecía autocumplida a la falsa profecía}

Según se acaba de exponer, el tema del tiempo afecta, por consiguiente, a la percepción de la ciudad (Curcic 2015). Existen otros aspectos de relieve en torno a la cronología que tienen que ver no tanto con el pasado (caso de la ciudad) cuanto con lo no acaecido, con lo futurible. Así, el plazo que se da a sí mismo 


\section{ANGÉLICA García-MAnso/ Francisco Javier Tovar PaZ}

Eric es de un día, de la mañana a la noche, según un modelo de "profecía autocumplida", es decir, de evolución sicológica del personaje desde el reconocimiento de la ruina económica hasta la aceptación de su propia muerte. De cualquier forma, en tanto el texto de DeLillo fue escrito con anterioridad a la crisis financiera del año 2008, convirtiéndose así el relato en la profecía de un futuro aún no acontecido, el filme de Cronenberg posee el carácter de "futuropasado" o "falsa profecía", realizado una vez consumado el colapso bursátil. Ello implica que la idea de profecía autocumplida se hace más palpable en el filme que en la novela.

De cualquier forma, cabe preguntarse dónde confluyen ambas tendencias, la del futuro en la novela y la del "futuro-pasado" en la película: la respuesta puede radicar precisamente en la noción de tiempo que hemos ido descubriendo en epígrafes precedentes. En efecto, es a partir de las diferentes percepciones del tiempo desde donde Cronenberg reformula hacia la estética fílmica la narración de DeLillo y, de alguna manera, convierte la decisión de morir de Eric en una reflexión que se podría calificar de "heideggeriana" (Chandler 2009): el discernimiento de que ser y tiempo son indisolubles. Ello resulta coincidente con el conocido tema de la "maquinización" desde el que se aborda en buena medida la estética de Cronenberg e incluso su vocación por el Séptimo Arte, una de las formas a las recurre para reflexionar sobre la concepción del tiempo y de sus límites físicos. En otras palabras, en tanto en DeLillo el relato parece acelerado, abocado a dar cumplimiento de su destino -un destino deliberado, que solamente sopesa la conciencia y voluntad de la autodestrucción-, en Cronenberg el mismo relato se revela ralentizado, autoconsciente de que es precisamente en la máxima detención del reloj donde radica la posibilidad de comprender y comprenderse. La forma de detener el reloj es necesariamente distinta en una obra escrita que en la filmación de imágenes.

Así, en cuanto a la película en torno a la concentración del tiempo, a su implosión, la elección del interior de un vehículo - una limusina- como escenografía y, a su vez, metáfora del propio personaje -en coincidencia con una de las formulaciones estéticas más reconocibles del director de Crash (1996) a la hora de fundir carne y metal- resulta conmovedora en los límites de la pantalla ${ }^{4}$. $\mathrm{Y}$ es que en la imagen fílmica la acción sucede básicamente en dos planos

${ }^{4}$ Se da así cumplida referencia a corrientes contemporáneas del pensamiento filosófico acerca del cine como arte del tiempo, según se descubre desde las reflexiones de Bergson a las de Deleuze (cf. Deleuze 2009, tanto sobre el pensamiento de Bergson y su influencia en Deleuze como sobre el mismo pensamiento de Deleuze) y Pardo (1990, también a partir de las reflexiones de Deleuze), según se van a considerar en el próximo epígrafe, dedicado a la relación entre la lectura profunda del filme contemporáneo con las paradojas temporales del antiguo filósofo griego Zenón de Elea. 
temporales: el del interior del vehículo y el del exterior que se intuye a través de sus cristales, como espacios también diferentes: es dentro del coche donde el reloj en funcionamiento es el del cuerpo (con sus ciclos sexuales y médicos), en tanto el mundo exterior aparece fuertemente ralentizado, avanzando por la ciudad a diez kilómetros por hora a la vez que insonorizado, lo cual ofrece la percepción subjetiva de que el cronómetro se ha detenido (Peterle 2016).

Por lo demás, en las escenas que tienen lugar fuera del vehículo, el tiempo se llena de elipsis en una trama que en su estructura más sencilla se limita, como se ha apuntado ya, al trayecto de un día, de la mañana a la noche, bajo la excusa de ir a hacerse un corte de pelo, pero que, en el fondo, se presenta como un viaje al pasado. No se trata sólo de un pasado lejano, sino del pasado reciente pero percibido como borroso en los diferentes encuentros con la esposa, cuando no se han cumplido aún tres semanas desde que contrajeron matrimonio (por lo demás, ambos pasados convergen en el hecho de que ni el maduro peluquero ni la ausente esposa llegan a entrar en la limusina) ${ }^{5}$.

Según hemos señalado con el ejemplo del filme Crash, tiempo y medio mecánico se funden de nuevo conforme es habitual en la estética de Cronenberg. Así lo refleja también el hecho de que el protagonista se pregunte continuamente por el destino nocturno de esos coches de lujo tan característicos de Nueva York incide en la mimetización entre el personaje y el vehículo, sin llegar a la nave industrial en la que Léos Carax hace hablar a sus coches en el filme Holy Motors (2012), estrenado casi simultáneamente con el de Cronenberg. En definitiva, la esencia fílmica de Cosmópolis se apoya en lo que sucede en el vehículo, allí donde colisionan el tiempo del interior y el del exterior, de forma concomitante a como sucede al espectador de cine que se hace partícipe de dos tiempos, el propio y el que se da en la pantalla ${ }^{6}$.

${ }^{5}$ De forma llamativa, por cuanto revela indirectamente la percepción globalizada e intercambiable en el mundo contemporáneo, el filme no está rodado en su mayor parte en Nueva York, sino en la ciudad canadiense de Toronto.

${ }^{6}$ En Holy Motors la limusina se convierte en un abigarrado camerino donde el protagonista se disfraza y maquilla para emular al hombre de las mil caras, precisamente a la manera del conocido actor Lon Chaney, de forma que irá transformándose, sucesivamente, en jorobado de Notre-Dame, Fantasma de la Ópera, en diferentes producciones mudas, así como el Alonzo de Garras Humanas (The Unknown, 1927, de Tod Browning) o el protagonista de The Monster (1925, dirigida por Roland West), etcétera, hasta culminar una docena de papeles. Por lo demás, el carácter metacinematográfico del filme se muestra desde sus inicios, con imágenes de King Vidor y sueños sobre presencias en la platea, y se mantiene al final, al mostrar una relación familiar del personaje con dos chimpancés, si bien el desenlace último sucede con un diálogo entre los mismos vehículos en una especie de cine "drive-in". Por lo demás, y de forma fuertemente llamativa, la programación de un suicidio tras un periplo en coche y con el leit-motiv de fondo del propio vehículo (un taxi) se aprecia también en el filme El sabor de las cerezas (Ta'm-e gilás, 1997), de Abbas Kiarostami. 


\section{La reflexión sobre el tiempo: la paradoja de Aquiles y la tortuga}

El tiempo como tema de reflexión en el relato no sólo se hace patente en las diferencias que ofrecen la confrontación entre el momento de la edición del texto y el de su plasmación cinematográfica, sino que se trata del leitmotiv central de la trama, pues continuamente se hace referencia a sus límites tanto en la novela como en el filme: sucede en las decisiones económicas, en las relaciones con la esposa, en el interior de la limusina, en las asimetrías, etcétera. Ello es síntoma de que la idea de tiempo posee un carácter clave, si bien, de nuevo, con matices, pues en el filme, al mostrar el interior de la limusina repleto de "gadgets" informáticos (Strombeck 2017), la noción de tiempo se presenta como la búsqueda del instante más pequeño, de la unidad ínfima, allí donde no existe lo humano, sino la tecnología que aporta lo inmediato y los cálculos macroeconómicos realizados en el mismo momento en que llega determinada información. En DeLillo más bien se trata de una cuestión semántica: es decir, acerca de si, teniendo en cuenta la inmediatez que permiten las nuevas tecnologías, es útil o necesario seguir empleando la palabra ordenador o computadora, dado que son meros cauces de decisiones humanas tomadas en el acto. Ello provoca la transformación de la condición de lo humano en virtual (Valentino 2007). De esta manera, de nuevo Cronenberg encuentra en el texto el tema de la interacción entre máquina y seres humanos al inscribir los aparatos informáticos como extensiones humanas, como el propio tiempo humano.

A este mismo respecto del tiempo como tema predominante, la edad del protagonista refuerza el enfoque cronológico presente en el relato con un nuevo dato, tanto en el encuentro con sus empleados técnicos (es decir, al margen del guardaespaldas y del chófer, con los que mantiene una mayor proximidad), siendo todos más jóvenes, como en sus encuentros sexuales, con mujeres de mayor edad que él: se trata de un nuevo ejemplo de tándem tecnología/humanidad. En este contexto, los encuentros sexuales, a pesar de su carácter mecánico, abogan por un deseo de humanización que coincide con el anhelo de muerte que constituye la esencia de la trama y que responde a la tradicional relación entre "eros" y "thánatos", o, también -según es, por lo demás, habitual en el director Cronenberg-, entre ser humano y máquina.

En fin, la duración cronológica del relato también deviene enfática, según se ha analizado en parágrafos precedentes, dado que la trama se desarrolla durante el período de un día, a lo largo del cual se concentran el éxito y el fracaso del personaje en tanto la ciudad, en ese mismo lapso temporal, se muestra ocupada por una visita del Presidente de los EEUU y por el funeral de un famoso rapero sufí. Así, establecido el tiempo como combinación simultánea de movimiento y estatismo como concepto clave a la hora de comprender la decisión del 
protagonista de programar su muerte, se entienden otros aspectos del relato, como, por ejemplo, la definición que hace el personaje de su oficina (entorno del que no se ofrecen imágenes): de una parte, una sala de tiro y, de otra, un ascensor que avanza a los lentos acordes de la música de Eric Satie. Se trata de una especie de bipolaridad que también se da en el ámbito de los deseos del personaje: la posesión de un enorme avión bombardero fabricado por el ejército ruso y la propiedad de la capilla del pintor Rothko en las cercanías de la ciudad de Houston.

De la colisión entre sendas opciones no surge un debate en el interior de Eric, dado que no parece mostrarse en "crisis" (ethymologico sensu), como si tal estado de ánimo no pudiera existir en un modo de vida y un sistema económico que actúan, precisamente, negando tal posibilidad, sino que hace emerger una situación eminentemente paradójica: la simultaneidad entre la aceleración y la inmovilidad, es decir, entre dos percepciones extremas del tiempo y el espacio.

En la Historia de la Cultura (dejando al margen lo que establece en el pasado las nociones del movimiento como kinesis en Aristóteles o el clinamen en el epicúreo Lucrecio, o, ya en tiempos contemporáneos, dejando también a un lado la Teoría de la Relatividad al respecto de la posición del observador respecto a si existe movimiento o detención) son las paradojas del filósofo presocrático Zenón de Elea las que mejor plantean la perspectiva del protagonista a la hora de negar realidad, espacio, tiempo y movimiento (Kirk et alii 1987). Su paradoja más conocida probablemente sea la de "Aquiles y la tortuga", la cual incluso posee trascendencia en la configuración del pensamiento platónico (Cavallar 2011). En dicha paradoja se plasma un duelo en el que el raudo Aquiles no puede vencer, pues no puede adelantar en la carrera al parsimonioso animal debido a que el héroe ha de atravesar infinitos espacios minúsculos antes de alcanzar a la tortuga (Echandi 1993). De esta manera, lo que sucede en el interior de la limusina va a ser continuamente negado por la imagen exterior: se trata de una negación que queda reducida, como en Zenón ${ }^{7}$, al absurdo: ¿Para qué cruzar la ciudad para cortarse el pelo cuando existen peluquerías junto al lugar donde se halla el protagonista? En otras palabras, se niega la posibilidad del movimiento y la existencia del tiempo a la vez que se concentra la acción en un desplazamiento a través del espacio de la metrópolis y dicha acción se desarrolla lo largo de un día solar. Qué duda cabe de que las aportaciones teóricas de la Filosofía tienen algo que decir, pero también de que DeLillo/Cronenberg plantean de manera

${ }^{7}$ También la paradoja zenoniana de la Flecha se expresa una posición de alternancia entre detención en el instante y sucesión del movimiento que resulta en cierta medida cinematográfica: el fotograma refleja la inexistencia del movimiento en tanto la película articula el movimiento. 
consciente un ejemplo irreal en la experiencia cotidiana, pero ejemplar en lo que se refiere a la intención última del relato.

Así, las intervenciones de palabra del guardaespaldas de Eric son las que, de continuo, ponen involuntariamente de manifiesto la incoherencia paradójica en la que se ha instalado el protagonista; y lo hacen porque está a caballo entre la limusina (mira al interior a través de las ventanillas con los cristales bajados) y la calle (aunque sin separarse del automóvil, como si, en verdad, fuera parte de éste). $\mathrm{El}$ asesinato de Torval se presenta de esta manera en varios niveles (Causo 2012): se trata de un acto arbitrario y síntoma de cómo el azar puede estar presente incluso contra aquellos cuyo oficio es ser su máximos controlador; se trata de demostrar por parte del personaje de Eric que mantiene la capacidad de decisión sobre las vidas ajenas de forma semejante a como funciona el sistema económico; también se trata de destruir a la única persona que, por su posición, conoce el punto débil, el talón, del personaje: el hecho de que puede estar arruinado. Pero, por otra parte, también la solución responde una decisión del protagonista para desmarcarse de la sensación de absurdo que continuamente le recrimina el guardaespaldas; de, una vez que la limusina ha sido deteriorada vandálicamente, destruir al personaje como daño colateral del propio vehículo; y se trata, en fin, de anticipar su propia muerte, como si ésta respondiera a un juego de ruleta rusa.

\section{Conclusión: Relecturas contemporáneas de la Tradición Clásica en Cosmópolis}

Si bien con las particularidades históricas y socioeconómicas derivadas del momento de su aparición (el libro es una década anterior a la película) y de las características propias de cada medio (la literatura o el cine), tanto la novela de DeLillo como el filme de Cronenberg se hacen acreedores de una lectura desde la perspectiva de la Tradición Clásica que permite enriquecer la comprensión del relato. Ciertamente, hay elementos puntuales en la novela, como la mención a la caída de Ícaro o-aunque desde una perspectiva ya religiosa si bien esta incumbe al Mundo Antiguo, a la primera cristiandad- una cita de San Agustín, que se desestiman en el filme. Entre los elementos compartidos entre texto y película, se comprueba cómo, a partir del recurso a la catábasis, se propone un viaje hacia una percepción de la urbe como necrópolis; también el motivo del desplazamiento remite al viaje odiseico hacia un reencuentro con la esposa, si bien, al cabo, tal reencuentro se revela imposible. Se trata meramente de dos ejemplos, entre otros que se han señalado, que reflejan cómo los motivos grecolatinos constituyen parte relevante del arquetipo del relato. En verdad, el trasfondo clásico se ve tamizado por otras lecturas más próximas en la historia literaria, como puede ser el Ulysses de Joyce, de tal forma que se da una especie 
de "meta-tradición clásica" como recurso que explica la peripecia vital del personaje.

Pero es en el ámbito de las divergencias o diferencias entre novela y película, en el que se descubre cómo, desde la perspectiva de la Tradición Clásica, la propuesta de Cronenberg se basa en un tema formal: la ralentización de los acontecimientos -o de las imágenes, por ser más coherentes con el carácter del medio cinematográfico-, la cual deviene extraña frente a la inmediatez que propugna en la contemporaneidad los sistemas informáticos objeto nuclear del tema que se aborda en la novela. Se trata de una aparente contradicción que posee un sustrato clásico en la paradoja, casi transformada en fábula, de Aquiles y la Tortuga. Aplicada la paradoja en el filme, Cronenberg convierte al personaje de Eric en un Aquiles que domina los tiempos inmediatos de la especulación monetaria y que, sin embargo, es vencido por la lentitud de los tiempos de la vida real, aquellos que permiten no sólo distinguir pasado y presente sino los tiempos de los demás, de los que no son uno mismo.

Finalmente, es la novela la que ofrece la imagen más dantesca en el sentido de combinar la presencia de cuerpos y muerte, pero que, anticipa, irónicamente, la adaptación fílmica (con un llamativo argumentum ex silentio por parte del filme cuando omite esta escena, como si, en apariencia, no encajara.). Y es que también Cronenberg, al cabo, utiliza el medio fílmico como vehículo de la ironía, que, en su sentido literal, consiste en la negación de lo evidente, y ello en cada plano y en cada relación o cruce entre personajes. Así, la premisa de la paradoja que envuelve a Aquiles se convierte en reflejo preciso de la ironía de la cronología en una ciudad de Cosmópolis que parece haber renunciado a su existencia al renegar del tiempo a cambio del instante.

\section{Referencias bibliográficas}

Causo, Massimo, "Cosmopolis. David Cronenberg: Il mondo interno dell'esterno dell'interno". En: Cineforum, 515, 2012, pp. 4-7.

CAVALLAR, Jonathan, "Las paradojas del movimiento de Zenón de Elea y el testimonio platónico". En: Aporía: revista internacional de investigaciones filosóficas, 2, 2011, pp. 77-93.

CHANDlER, Aaron, "An Unsetting, Alternative Self”: Benno Levin, Emmanuel Levinas and Don DeLillo's Cosmopolis". En: Critique: Studies in contemporary Fiction, 50, 2009, pp. 241-260.

Clavin, Keith, "Narrating Risk: the Finantial Thriller Film during the U.S. Recession”. En: Textual Practice, 31, 2017, pp. 477-490.

CurciC, Miroslav, "Don DeLillo's Point Omega: Discourses of Time, Space and Consciousness". En: Lopičić, Vesna \& Mišić-Ilić, Biljana (eds.), Jęiik, 
ANGÉLICA García-MANSO/ Francisco Javier TOVAR PaZ

književnost, diskurs: književna istraživanja. Niš: Universitet u Nišu, 2015, pp. 509 520 .

Deleuze, Gilles, Cine I: Bergson y las imágenes. Buenos Aires: Cactus, 2009.

DeLillo, Don, Cosmopolis. Barcelona: Seix Barral, 2004.

Duvall, John N., The Cambridge Companion to Don DeLillo. Cambridge: Cambridge University Press, 2008.

ECHANDi ERCILA, S., La fábula de Aquiles y Quelone: ensayos sobre Zenón de Elea. Zaragoza: Prensas Universitarias de Zaragoza, 1993.

García Jurado, Francisco, Teoría de la Tradición Clásica. Conceptos, historia y métodos. México: Universidad Nacional Autónoma de México, 2015.

GARRIGós, Cristina, "Death Drive and Desire in Cronenberg's Adaptation of DeLillo's Cosmopolis". En: Critique: Studies in Contemporary Fiction, 56, 2015, pp. 519-530.

GenetTe, Gérard, Palimpsestos. La literatura en segundo grado. Madrid: Taurus, 1989.

GorostizA, J.; PÉREZ PlasenciA, A., David Cronenberg. Madrid: Cátedra (reed.), 2003.

GRUGEAU, Gérard, “L'homme flambé/Cosmopolis de David Cronenberg”. En: 24 Images, 158, 2012, pp. 62-63.

HeIDEGGER, Martin, Ser y tiempo. Madrid: Trotta, 2012.

HEYNE, Eric, "A Bruised Cartoonish Quality": The Death of an American Supervillain in Don DeLillo's Cosmopolis". En: Critique: Studies in Contemporary Fiction, 54, 2013, pp. 438-451.

KIRK, G. S.; RAVEN, J. E.; SCHONFIELD, M., Los filósofos presocráticos. Madrid: Gredos (reed.), 1987.

LAIST, Randy, “The concept of dissapearance in Don DeLillo's Cosmopolis". En: Critique: Studies in Contemporary Fiction, 51, 2010, pp. 257-275.

LEPS, Marie-Christine, "How to map the non-place of empire: DeLillo's Cosmopolis”. En: Textual Practice, 28, 2014, pp. 305-327.

LIPOVETSKY, Gilles, La era del vacio. Barcelona: Anagrama, 1994.

MerolA, N. M., "Cosmopolis: Don DeLillo’s Melancholy Political Ecology”. En: American Literature: A journal of literary history, criticism and bibliography, 84, 2014, pp. 827-852.

MirbabAZADE, Fateme Seyyede; JAFARI, Alizera, "Consumption as Sign in Don DeLillo's Cosmopolis". En: International Journal of Applied Linguistics and English Literature, 2, 2013, pp. 67-75.

Noble, Stuart, "Don DeLillo and Society's Reorientation to Time and Space: An Interpretation of Cosmopolis". En: Aspeers: Emerging voices in American Studies, 1, 2008, pp. 57-70. 
Otero Furelo, M. A., "Cosmópolis, de Don DeLillo". En: Eduga: revista galega do ensino, 43, 2004, pp. 236-238.

PARDO, José Luis, Deleuze: violentar el pensamiento. Madrid: Cincel, 1990.

PeterLE, Giada, "Moving Literature: the car as a mobile chronotope in Don DeLillo's Cosmopolis". En: Rivista geográfica italiana, 3, 2016, pp. 281-300.

RODICA, Mihaila, "Deconstructing the "rags to riches" Etos in the Recent American Novel: DeLillo's *Cosmopolis* and Cormac McCarthy's *The Road*”. En: Gurpegui Palacios, J. A. y Durán Giménez-Rico, I. (edd.), The Backyard of the U. S. Mansion. Alcalá de Henares (Madrid): Universidad de Alcalá, 2012, pp. 89-100.

SÁnCHeZ Bravo, E., "Aspectos filosóficos en la obra de Don DeLillo: tiempo, arte, cibercapital, y muerte en la postmodernidad". En: Paradoxa, 16, 2014, pp. 243-301.

SCIOLINO, Martina, "The Contemporary American Novela as World Literature: The Neoliberal Antihro in Don DeLillo's Cosmopolis". En: Texas Studies in Literature \& Language, 57, 2015, pp. 210-241.

Strombeck, Andrew, "The Limousine and Technicity in Don DeLillo's Cosmopolis". En: MFS. Modern Fiction Studies, 63, 2017, pp. 146-167.

TOVAR PAZ, Francisco Javier, "Las puertas de los sueños auténticos y de los sueños falaces en la película Eyes Wide Shut (1999), de Stanley Kubrick". En: VV.AA., Homenaje a la profesora Carmen Pérez Romero. Cáceres: Facultad de Filosofía y Letras de la Universidad de Extremadura, 2000, pp. 365-372.

-, "De Lucrecio a Benjamin Christensen: un análisis comparado de dos manifestaciones del género didáctico". En: Anuario de Estudios Filológicos, 30, 2007, pp. 423-438.

—, La Delgada Linea Roja, de Terrence Malick: Contempla la secuencia de los combates. Madrid: Akal, 2012.

VALENTinO, Russell Scott, "From Virtue to Vitual: DeLillo's Cosmopolis and the Corruption of the Absent Body". En: MFS. Modern Fiction Studies, 53, 2007 , pp. $140-162$. 